\title{
Article
}

\section{Preparation of New Functionalized Graft Polymers and Their Application as Supports in Organic Synthesis}

\author{
Makoto KOMATSU, Masayoshi KANEKO, Kunio FUJIWARA, Kazuyoshi TAKEDA \\ Ebara Research Co., Ltd., 4-2-1 Honfujisawa, Fujisawa-shi, Kanagawa 251-8502, Japan
}

(Manuscript submitted February 11, 2003; accepted April 18, 2003)

\begin{abstract}
New functionalized graft polymers ( $\mathrm{fCMS}-\mathrm{Br}_{3}, \mathrm{fCMS} \mathrm{BH}_{4}$ ) were synthesized from an anion-exchange fiber, which was prepared using radiation-induced graft polymerization. The abilities of these polymers as polymer-supported reagents are discussed. After bromination of $p$-cresol and reduction of benzaldehyde with these polymers in a column-mode, the relationship between flow rate and product yield was examined, and compared with the results of the polymer-supported reagents prepared from a porous resin. In both cases, the present graft polymers provided the desired compounds more efficiently even at a high flow rate.
\end{abstract}

\section{Introduction}

A large number of polymer-supported reagents have been reported, and some of them are widely used in organic synthesis.[1,2] However, both stirring during the reactions and filtration to remove reagents after the reactions have been required in almost all previous studies. These workups will be troublesome in the case of large-scale reactions. Due to these drawbacks, few examples of the utilization of polymer-supported reagents have been reported in the chemical industry. In order to solve this problem, a column-mode reaction is preferred. However, in previous studies, the effect of flow rate on the yield and availability of the functional group have not yet been studied.

Radiation-induced graft polymerization is a versatile technique for introducing various functionalities onto base polymers in a wide range of shapes.[3,4] By adopting this technique, we have tried to attach reactive functional groups onto a polyethylene fiber. As shown in Fig.1, after graft polymerization of chloromethylstyrene (CMS), the anion-exchange group was introduced onto the graft side chain, and changed to the tribromide form ( $\left.\mathrm{fCMS}-\mathrm{Br}_{3}\right)$ as a brominating agent and the borohydride form $\left(\mathrm{fCMS}-\mathrm{BH}_{4}\right)$ as a reducing agent.
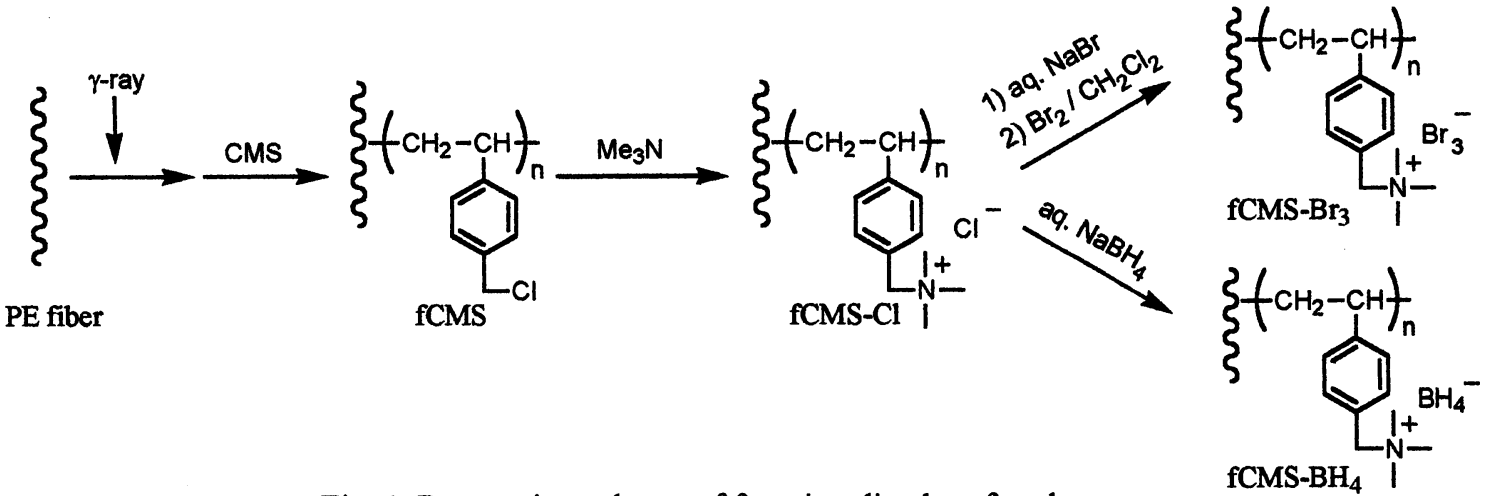

Fig. 1 Preparation scheme of functionalized graft polymers. 
Similarly, porous polymer-supported reagents were also prepared from a commercially available anion-exchange resin.[5-7] The bromination of $p$-cresol and reduction of benzaldehyde was carried out by passage through the column packed with these polymers. This paper deals with the effect of flow rate on the product yield in the column-mode reactions.

\section{Experimental}

\subsection{Immobilization of anion-exchange group on polyethylene fiber}

A commercially available non-woven fabric (Japan Vilene Co., Japan) was used as the base polymer. It has a density of $50 \mathrm{~g} / \mathrm{m}^{2}$ and is made of polyethylene (PE) fiber having about a 10-16 $\mu \mathrm{m}$ diameter. Technical-grade chloromethylstyrene (CMS) contains more than $95 \%$ of the $p$-isomer (Seimi Chemical Co., Japan), and it was used after purification with basic alumina (ICN Biomedicals, Inc., Germany). The polyethylene non-woven fabric $(40 \mathrm{~g})$ was irradiated with $\gamma$-rays at $160 \mathrm{kGy}$ with cooling on dry ice. This irradiated base was immersed in CMS and reacted at $50{ }^{\circ} \mathrm{C}$ for $5 \mathrm{~h}$ to give $80 \mathrm{~g}$ of the CMS-grafted fiber (fCMS) with a grafting degree of $100 \%$. This grafted fiber fCMS $(24.0 \mathrm{~g})$ was immersed in a solution of trimethylamine $(520 \mathrm{mmol}, 30.8 \mathrm{~g})$ in water $\left(320 \mathrm{~cm}^{3}\right)$ and isopropanol $\left(160 \mathrm{~cm}^{3}\right)$, and reacted at $50{ }^{\circ} \mathrm{C}$ for $24 \mathrm{~h}$. After the reaction, the sample was successively washed with water, $0.1 \mathrm{~mol} / \mathrm{dm}^{3}$ hydrochloric acid and water, and then dried at $50{ }^{\circ} \mathrm{C}$ for $6 \mathrm{~h}$ to give the anion-exchange fiber, fCMS-Cl (30.1 g). The anion-exchange capacity was $2.02 \mathrm{meq} / \mathrm{g}$ or $338 \mathrm{meq} / \mathrm{m}^{2}$.

\subsection{Preparation of polymer-supported brominating agents}

The anion-exchange fiber, fCMS-Cl (10.2 g), was immersed in a $15 \%$ aqueous solution of sodium $\mathrm{NaBr}$ $\left(200 \mathrm{~cm}^{3}\right)$ and reacted at room temperature for $12 \mathrm{~h}$. The sample was washed with water and dried at $50{ }^{\circ} \mathrm{C}$ for 6 $\mathrm{h}$ to give the anion-exchange fiber, $\mathrm{fCMS}-\mathrm{Br}(11.1 \mathrm{~g})$. The resultant fiber was immersed in a solution of bromine ( $3.7 \mathrm{~g}, 23.3 \mathrm{mmol})$ in $\mathrm{CH}_{2} \mathrm{Cl}_{2}\left(500 \mathrm{~cm}^{3}\right)$ and reacted at room temperature for $12 \mathrm{~h}$. The sample was washed with $\mathrm{CH}_{2} \mathrm{Cl}_{2}$ and dried overnight at $40{ }^{\circ} \mathrm{C}$ to afford the brominating agent, $\mathrm{fCMS}-\mathrm{Br}_{3}$, as a yellow fiber $(15.4 \mathrm{~g})$. After

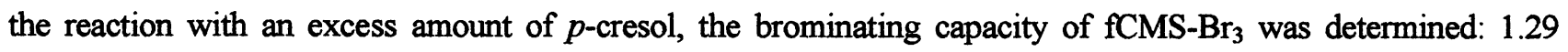
$\mathrm{meq} / \mathrm{g}$ or $322 \mathrm{meq} / \mathrm{m}^{2}$. A porous brominating agent was prepared from the Amberlyst A-26 Br- (Fluka Chemie, Germany) in the same manner as described above, whose brominating capacity was $2.30 \mathrm{meq} / \mathrm{g}$.

\subsection{Preparation of polymer-supported reducing agents}

The anion-exchange fiber, fCMS-Cl $(6.83 \mathrm{~g})$, was immersed in a $0.5 \%$ aqueous solution of sodium borohydride $\left(200 \mathrm{~cm}^{3}\right)$ and reacted at room temperature for $1 \mathrm{~h}$. The sample was washed with water and dried at $50{ }^{\circ} \mathrm{C}$ for $6 \mathrm{~h}$ to afford the reducing agent, $\mathrm{fCMS}-\mathrm{BH}_{4}$, as a white fiber $(6.50 \mathrm{~g})$. After the reaction with an excess amount of benzaldehyde, the reducing capacity of $\mathrm{fCMS}^{-\mathrm{BH}_{4}}$ was determined: $7.79 \mathrm{meq} / \mathrm{g}$ or $1144 \mathrm{meq} / \mathrm{m}^{2}$. Accordingly, the content of the borohydride was calculated to be $1.95 \mathrm{mmol} / \mathrm{g}$ or $286 \mathrm{mmol} / \mathrm{m}^{2}$. A porous reducing agent was prepared from Amberlite IRA900J Cl (Rohm \& Hass Co., USA) in the same manner, whose reducing capacity was $9.76 \mathrm{meq} / \mathrm{g}$.

\subsection{Bromination of $p$-cresol by column-mode}

Column-mode reaction was performed using the apparatus shown in Fig. 2 using a Masterflex 7553-80 pump (d) and Viton 06412-16 tube (e) (Cole-Parmer Co., USA). A stack of $18 \mathrm{~mm}$ diameter $\mathrm{fCMS}-\mathrm{Br}_{3}$ or the Amberlyst A-26 $\mathrm{Br}_{3}^{-}$form was packed into a glass column (a) having an inner diameter of $18 \mathrm{~mm}$ (bed height $50 \mathrm{~mm}$, bed volume 12.7 $\mathrm{cm}^{3}$ ). After conditioning the column by passing $\mathrm{CH}_{2} \mathrm{Cl}_{2}$, a solution of p-Cresol 1 in $\mathrm{CH}_{2} \mathrm{Cl}_{2} / \mathrm{MeOH}\left(40 \mathrm{~cm}^{3} / 10 \mathrm{~cm}^{3}\right)$, and then $\mathrm{CH}_{2} \mathrm{Cl}_{2}-\mathrm{MeOH}$

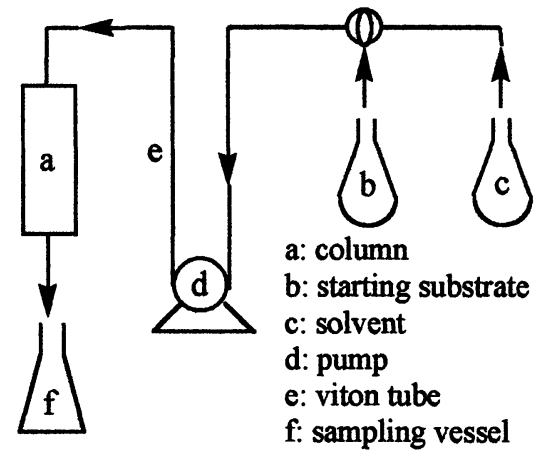

Fig. 2. Column-mode reaction apparatus 
$(\mathrm{v} / \mathrm{v}=4 / 1)$ were passed successively through the column at room temperature. The obtained effluent $\left(100 \mathrm{~cm}^{3}\right)$ was concentrated and treated with a $5 \%$ aqueous solution of $\mathrm{NaHSO}_{3}\left(50 \mathrm{~cm}^{3}\right)$, and the mixture was extracted with ether $\left(40 \mathrm{~cm}^{3} \times 3\right)$. The organic layer was dried, concentrated in vacuo, and the recovery of each compound was determined by ${ }^{1} \mathrm{H}$ NMR.

\subsection{Reduction of benzaldehyde by column-mode}

A stack of $\mathrm{fCMS}-\mathrm{BH}_{4}$ or the Amberlite IRA900J BH 4 form was packed into the column (a) (bed height 28 $\mathrm{mm}$, bed volume $7.3 \mathrm{~cm}^{3}$ ). After conditioning the column by passing EtOH, a solution of benzaldehyde 4 (1.6 $\mathrm{mmol})$ in $\mathrm{EtOH}\left(50 \mathrm{~cm}^{3}\right)$, and then EtOH were passed through the column at room temperature. The obtained effluent $\left(100 \mathrm{~cm}^{3}\right)$ was concentrated, and the recovery of each compound was determined by ${ }^{1} \mathrm{H}$ NMR.

\subsection{Measurement of products in effluent}

The ${ }^{1} \mathrm{H}$ NMR spectra were recorded using a $400 \mathrm{MHz}$ FT-NMR spectrometer (Bruker, AVANCE DRX-400) for solutions in $\mathrm{CDCl}_{3}$ using TMS as an internal standard. The concentrations of the compounds (1-3) were determined by integration of the corresponding ${ }^{1} \mathrm{H}$ NMR spectra, the signal of the 2- and 6-positions $(\delta 6.73 \mathrm{ppm}$, $2 \mathrm{H})$ for 1 , the signal of the 6-position $(\delta 6.91 \mathrm{ppm}, 1 \mathrm{H})$ for $2, \mathrm{CH}_{3}$ signal $(\delta 2.26 \mathrm{ppm}, 3 \mathrm{H})$ for 3 , and the signal $(\delta 5.95 \mathrm{ppm}, 2 \mathrm{H})$ for 1,1,2,2-tetrachloroethane used as the internal standard. The concentrations of the compounds $(4,5)$ were determined in the same manner as described above, the formyl signal $(\delta 10.00 \mathrm{ppm}, 1 \mathrm{H})$ for 4 , and $\mathrm{CH}_{2}$ signal $(\delta 4.68 \mathrm{ppm}, 2 \mathrm{H})$ for $\mathbf{5}$, and the signal for 1,1,2,2-tetrachloroethane.

\section{Results and Discussion}

\subsection{Bromination of $p$-cresol by column-mode}

In the case of both brominating agents, the yields of the brominated compounds $(2,3)$ increase as the flow rate decreases (Table 1). Remarkably, comparing the yield between the two agents under the same flow rate, fCMS- $\mathrm{Br}_{3}$ can provide brominated compounds in higher yield in spite of the lower equivalent of functional groups. Especially, 2,6-dibromo-4-methylphenol 3 was obtained in extremely high yield at a flow rate $0 \mathrm{~cm}^{3} / \mathrm{min}$. Consequently, $\mathrm{fCMS}-\mathrm{Br}_{3}$ has a higher ability as a brominating agent than the corresponding porous resin. This can be understood for the following reasons. In the case of the Amberlyst A-26 $\mathrm{Br}_{3}$ form, the diffusion of the starting material into the interior side of the resin is required for contact with the reactive functional groups. Therefore, as

Table 1. Effect of flow rate on product yield during the column-mode bromination of $p$-cresol

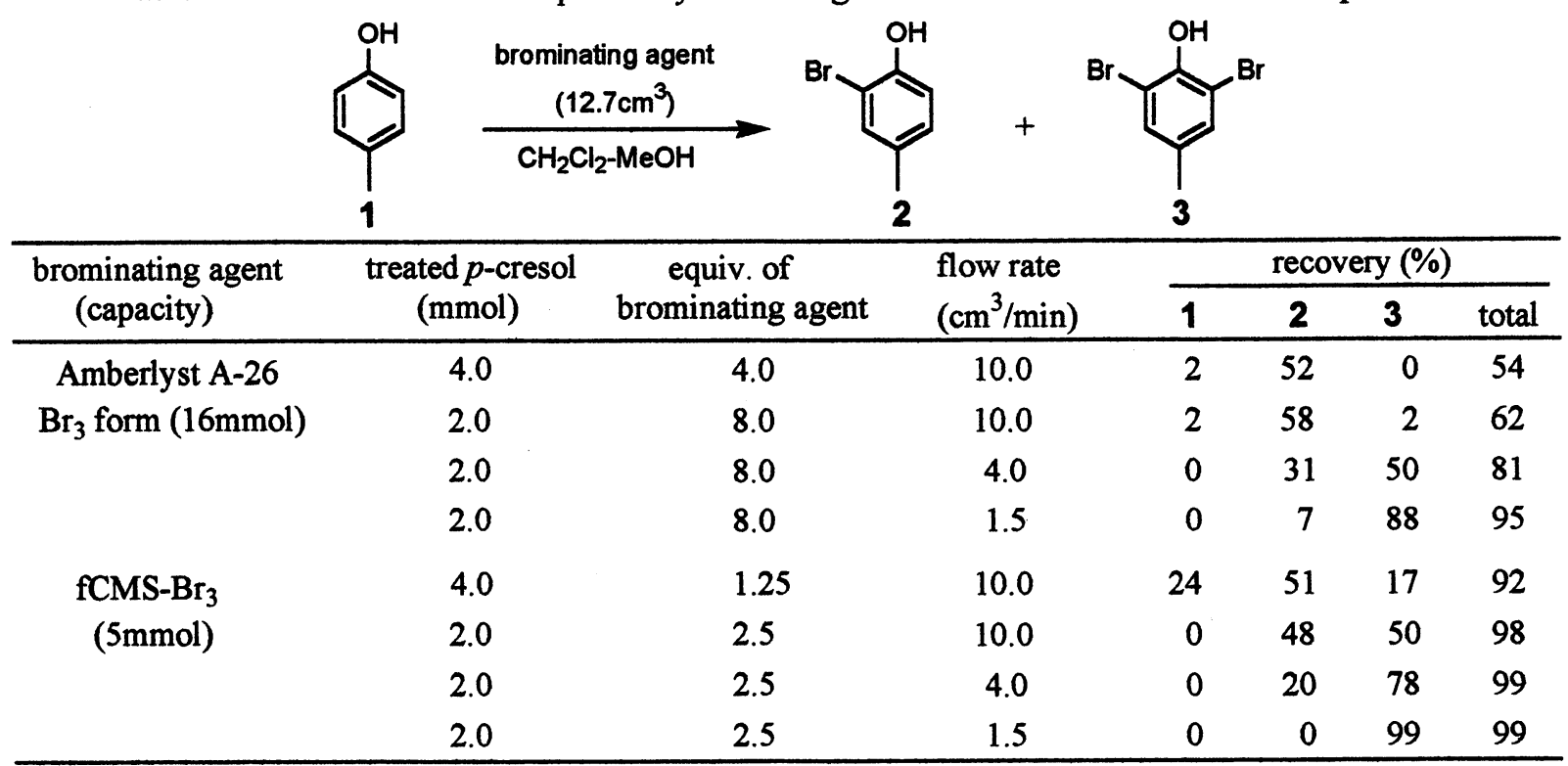


flow rate increases, the starting material passes through the column without any contact with the functional groups, although the resin has a high specific surface area on the interior side. On the contrary, in the case of $\mathrm{fCMS}_{\mathrm{Cr}} \mathrm{Br}_{3}$, the starting material can efficiently approach the surface of the fiber, i.e., the reactive functional groups, by passing through the column. In addition, the graft chain having reactive functional groups is swollen in the solvent, so that it contributes to the efficiency of the reaction. Moreover, fCMS- $\mathrm{Br}_{3}$ can also provide a higher total recovery of the compounds (1-3), because, in the case of the porous resin, diffusion of the compounds to the outer side of the resin have not finished when using $100 \mathrm{~cm}^{3}$ of effluent. Accordingly, additional solvent flow is required in order to provide a higher total recovery.

\subsection{Reduction of benzaldehyde by column-mode}

After evaporation of the effluent, the compounds $(4,5)$ can be obtained as pure samples without any further treatment. In the case of both reducing agents, the yields of benzylalcohol 5 increase as the flow rate decreases (Table 2). In addition, comparing the yield between the two agents at the same flow rate, $\mathrm{fCMS}-\mathrm{BH}_{4}$ can provide the benzylalcohol 5 in higher yield in the same way as described above.

Table 2. Effect of flow rate on product yield during the column-mode reduction of benzaldehyde

\begin{tabular}{|c|c|c|c|c|c|c|}
\hline \multirow{2}{*}{$\begin{array}{l}\text { reducing agent } \\
\text { (capacity) }\end{array}$} & \multirow{2}{*}{$\begin{array}{c}\text { equiv. of } \\
\text { reducing agent }\end{array}$} & \multirow{2}{*}{$\begin{array}{l}\text { flow rate } \\
\left(\mathrm{cm}^{3} / \mathrm{min}\right)\end{array}$} & \multicolumn{3}{|c|}{ recovery (\%) } & \multirow{2}{*}{$\begin{array}{c}5 / \text { tota } \\
(\%)\end{array}$} \\
\hline & & & 4 & 5 & total & \\
\hline Amberlite IRA900J & 11.6 & 10.0 & 56 & 16 & 72 & 22 \\
\hline $\mathrm{BH}_{4}$ form $(18.6 \mathrm{mmol})$ & 11.6 & 2.0 & 14 & 41 & 55 & 75 \\
\hline \multirow{3}{*}{$\begin{array}{r}\mathrm{fCMS}^{-\mathrm{BH}_{4}} \\
(6.4 \mathrm{mmol})\end{array}$} & 4.0 & 10.0 & 16 & 78 & 94 & 83 \\
\hline & 4.0 & 5.0 & 4 & 81 & 85 & 95 \\
\hline & 4.0 & 2.0 & 0 & 84 & 84 & 100 \\
\hline
\end{tabular}

This naturally indicates that the present graft polymers are valuable polymer-supported reagents, which can provide the desired compounds much more efficiently than the porous resin in the column-mode reaction. Furthermore, by searching the more suitable functional groups and base polymers, it is expected that graft polymers will become versatile reagents that can be applied to large-scale reactions in the chemical industry.

\section{Acknowledgement}

We thank Dr. Takanobu Sugo and Naoko Murohashi of the Japan Atomic Energy Research Institute for their help in providing the irradiated non-woven fabric.

\section{References}

1) S. J. Shuttleworth, S. M. Allin, R. D. Wilson, and D. Nasturica, Synthesis 2000, No. 8, 1035-1074.

2) A. Kirschning, H. Monenschein, and R. Wittenberg, Angew. Chem. Int. Ed., 40, 650-679 (2001).

3) K. Saito, T. Kaga, H. Yamagishi, S. Furusaki, T. Sugo, and J. Okamoto, J. Membr. Sci., 43, 131-141 (1989).

4) H. Yamagishi, K. Saito, S. Furusaki, T. Sugo, and J. Okamoto, Nippon Kagaku Kaishi, 2, 212 -216 (1988).

5) T. Kakinami, H. Suenaga, T. Yamaguchi, T. Okamoto, and S. Kajigaeshi, Bull. Chem. Soc. Jpn., 62, 3373-3375 (1989).

6) K. Smith, D. M. James, I. Matthews, and M. R. Bye, J. Chem. Soc., Perkin Trans. 1, 1992, 1877-1878.

7) H. W. Gibson and F. C. Bailey, J. Chem. Soc. Chem. Comm., 22, 815 (1977). 